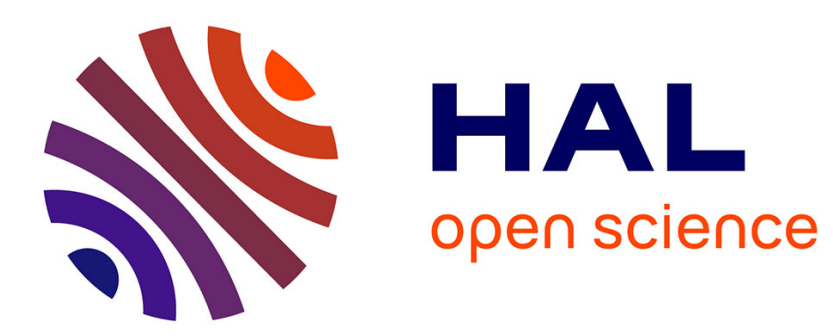

\title{
PATHBIO: an international training program for precision mouse phenotyping
}

Jesus Ruberte, Paul Schofield, Cord Brakebusch, Peter Vogel, Yann Herault, Guillem Gracia, Colin Mckerlie, Martin Hrabĕ de Angelis, Michael Hagn, John Sundberg

\section{To cite this version:}

Jesus Ruberte, Paul Schofield, Cord Brakebusch, Peter Vogel, Yann Herault, et al.. PATHBIO: an international training program for precision mouse phenotyping. Mammalian Genome, 2020, 31 (1-2), pp.49-53. 10.1007/s00335-020-09829-1 . hal-03065414

\section{HAL Id: hal-03065414 https://hal.science/hal-03065414}

Submitted on 27 Nov 2021

HAL is a multi-disciplinary open access archive for the deposit and dissemination of scientific research documents, whether they are published or not. The documents may come from teaching and research institutions in France or abroad, or from public or private research centers.
L'archive ouverte pluridisciplinaire HAL, est destinée au dépôt et à la diffusion de documents scientifiques de niveau recherche, publiés ou non, émanant des établissements d'enseignement et de recherche français ou étrangers, des laboratoires publics ou privés. 


\title{
PATHBIO: An International Training Program for Precision Mouse Phenotyping
}

Jesus Ruberte, ${ }^{1}$ Paul N. Schofield, ${ }^{2,8}$ Cord Brakebusch, ${ }^{3}$ Peter Vogel, ${ }^{4}$ Yann Herault, ${ }^{5}$ Guillem Gracia, ${ }^{1}$ Colin McKerlie, ${ }^{6}$ Michael Hagn, ${ }^{7}$ John P. Sundberg ${ }^{8}$

${ }^{1}$ Center for Animal Biotechnology and Gene Therapy, Dept. Health and Animal Anatomy Universitat Autònoma de Barcelona, Barcelona, Spain; ${ }^{2}$ University of Cambridge, Cambridge, UK; ${ }^{3}$ Biotech Research \& Innovation Centre, Univerisity of Copenhagen, Denmark; ${ }^{4}$ St. Jude's Children's Research Hospital, Memphis, TN, USA; ${ }^{5}$ Université de Strasbourg, CNRS, INSERM, PHENOMIN-ICS, Institut Clinique de la Souris, Illkirch, France; ${ }^{6}$ Toronto Center for Phenogenomics, Toronto, Canada; ${ }^{7}$ Helmholtz Zentrum Muenchen Deustsches Forschungszentrum fuer Gesundheit und Umwelt GMBH, Munich, Germany; and ${ }^{8}$ The Jackson Laboratory, Bar Harbor, ME, USA.

Corresponding author: Jesús Ruberte París

Dept. Health and Animal Anatomy, Autonomous University of Barcelona, Barcelona, Spain

Email: jesus.ruberte@uab.es

Phone: +34 935814187

FAX: +34935814205

Running Head: Mouse Phenotyping Training Program

Key Words: Mouse models, histology, embryology, anatomy, pathology, imaging technologies

\begin{abstract}
Large-scale production of mouse mutants using CRISPR/Cas9 technology by research laboratories or industry has created a need for qualified personnel to characterize (phenotype) the potentially new mouse models of human diseases. To meet this need, a series of teaching workshops will be given in Europe by some of the leading experts on anatomy, embryology and histology, modern imaging approaches, and comparative pathology and genetics. These workshops are open to all levels of investigators from recent graduates to Ph.D., M.D., and veterinary scientists. These workshops are available on a competitive basis at no cost for attending. The first series was held in 2019 and these will continue for the next two years.
\end{abstract}




\section{INTRODUCTION}

"The introduction of the use of inbred mice into cancer and other biological research has been a long and slow process.” (Strong 1942) Leonell C Strong, 1942

While this was once true, the laboratory mouse has long since become the premier system for modelling and understanding human diseases. Well characterized genetics and the ability to manipulate the mouse genome cheaply and easily has resulted not only in the rapid expansion of hypothesis-driven research, but also a large scale, internationally coordinated, targeted mutagenesis project focused on systematically inactivating all protein coding genes in the mouse genome one at a time (Bradley 2012). Combined with the impact of newer CRISPR/Cas9 approaches to creating orthologous mutations in mouse genes to validate human next-generation sequencing discoveries (Birling 2017) the need for precise, consistent, and reproducible phenotyping approaches has never been higher.

Despite the increasing demand for experts in mouse biology and pathology, there is a well-established deficiency of specialized training opportunities for veterinary and medical pathologists as well as biomedical researchers to acquire the necessary expertise, especially through formalized and recognized programs in Higher Education (Sundberg 2012). Currently no single European Institution has all the expertise, resources, and personnel required to design and establish a strong educational program in Mouse Precision Pathobiology, which integrates pathology, anatomy, embryology, imaging, ontologies, and informatics. For this reason PATHBIO was established as a Knowledge Alliance Initiative, to develop, organize, and deliver intensive specialized courses in Mouse Precision Pathobiology.

PATHBIO includes leading universities (UAB, UCAM, UCPH, FMV-ULisboa, Unina, and USFD) in the field. Furthermore, five major European mouse clinics (PHENOMINICS, MRC Harwell, HMGU, IMG, and CNR) equipped with integrated facilities for production and characterization of genetically engineered mouse models are also part of PATHBIO. These mouse clinics are developing and using state of art mouse imaging technologies and have long-standing expertise in phenotyping along with the datacapture, annotation, and bioinformatics analysis capabilities to interpret the resulting datasets. Three of the largest producers and suppliers of mouse models worldwide heavily involved in drug research (CHARLES RIVER, JAX and TCP Inc.) and a company leader in the field of preclinical imaging (FUJIFILM VISUALSONICS) are also essential partners of PATHBIO. FELASA and ICLAS, two important European and global animal science associations representing common interests in all aspects of laboratory animal science in Europe and beyond, are also integrated within the PATHBIO consortium. Finally, the interaction with the Asian, Australian, South American and African Phenogenomics centers as associate partners, provides PATHBIO with a unique and preeminent global position to define a common and fundamental skill set required for mouse phenotyping.

The PATHBIO program will deliver a series of three workshops in Europe this year and will provide an additional 6 over the next two years. Each year three modules are offered: 1) Anatomy, Embryology, and Histology, 2) Advanced Imaging Technologies, and 3) Comparative Pathology. The target audience includes undergraduates, graduate students, and principal investigators. This program is not designed to train veterinarians 
and physicians to become board certified pathologists, but rather to introduce a wide range of people to the variety of technologies available, give them some hands-on experience, and introduce them to many of the best specialists in this broad field.

To accommodate veterinarians and physicians, especially board certified pathologists and pathology residents, highly specialized meetings are available elsewhere, such as the Annual Pathology of Mouse Models of Human Diseases Workshop held at The Jackson Laboratory every October (Sundberg 2018). Similar pathologist focused training programs are being developed and scheduled in Europe and South America.

\section{The PATHBIO training modules}

1. Anatomy and histology.

The first workshop was held 15-26 July 2019 at the Veterinary School, Autonomous University of Barcelona in Spain (Fig. 1) with the next to be held there 6-18 July 2020. This module covered gross and microscopic (histologic) anatomy and embryology, and the

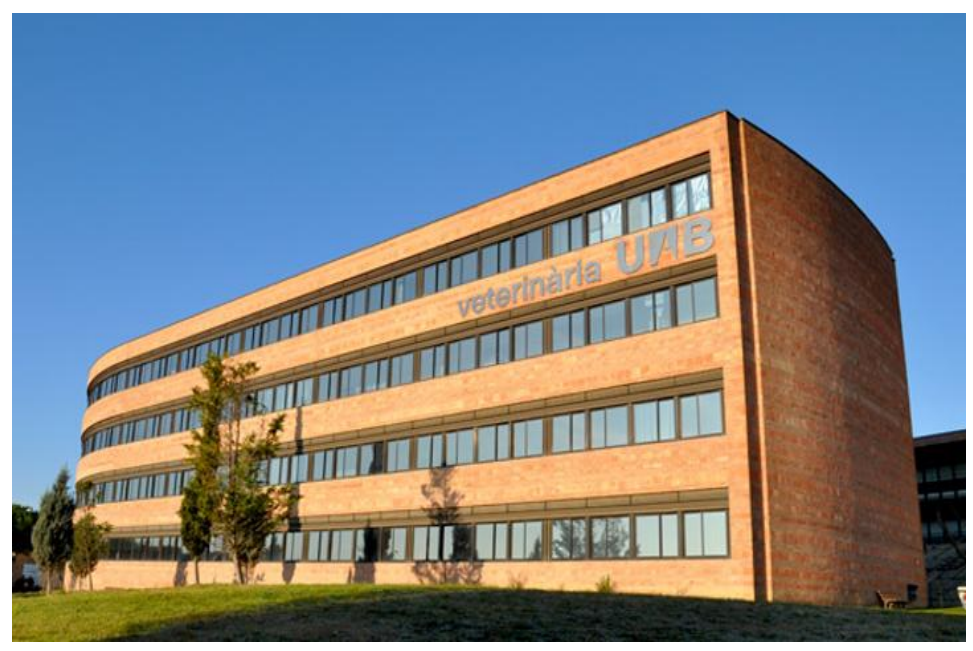

morphological basis of imaging of the major organ systems, which included how organs changed with age from newborn to geriatric mice. Lectures included details on organs that cycle, such as hair follicles and the female reproductive tract. Examples of abnormalities, using established mutant mouse models, illustrated the value of investigating each organ system in detail. Interactive sessions utilized whole slide scanned images that are open access to using Pathbase (http://www.pathbase.net/) (Schofield 2004a; Schofield 2004b; Schofield 2010). Anatomical demonstrations were given to show students how to identify the major organs as well as structures that can be difficult to find, specifically lymph nodes. This approach provided a broad overview of anatomy, embryology and histology for entry-level technicians to junior faculty members lacking this type of specialized, mouse-specific training. Similar programs have historically been offered for Ph.D. students and principal investigators with no pathology training by the American Association for Cancer Research and other organizations with a specific disease or organ focus, but none with as comprehensive approach as provided in this module. 


\section{Advanced Mouse}

Imaging Technologies.

This module will be held in Strasbourg, France, 4-8 November 2019 (Fig. 2), with the next workshop being held at the same site and the same month in 2020. Imaging technologies provide powerful tools to help us to understand and follow the progress of

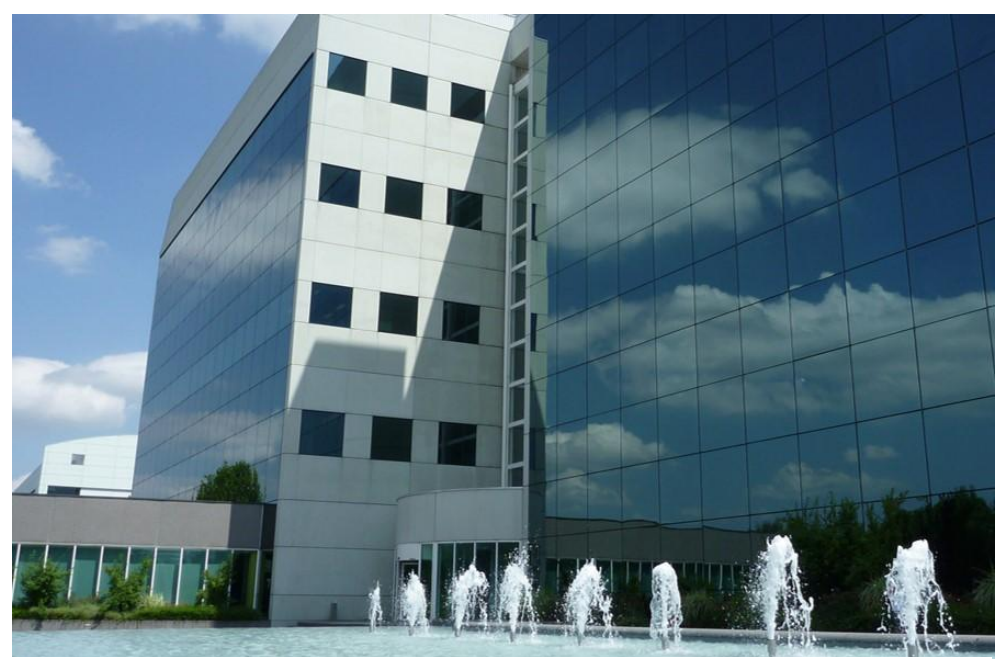
diseases in humans as well as in mouse models. They offer the opportunity to characterize morphologically and functionally disease models using a wide variety of methods. Most of these are translational as the technologies were initially developed for analyzing human patients and later adapted to mouse models. This PATHBIO module will cover the "state of art" for the most relevant imaging techniques used in mice, such as X-ray, microCT, MRI, OPT, HREM, optoacoustic imaging, echography, intravital microscopy, as well as the basis for image analysis and 3D rendering. Small working groups will be provided hands-on training.

3. Pathology of Mouse Models. This workshop was held 26-30 August 2019 and will be held 24-28 August 2020 at the University of Copenhagen (Fig. 3). Lectures covered histology and pathology basics, as most participants did not attend the anatomy module held earlier in

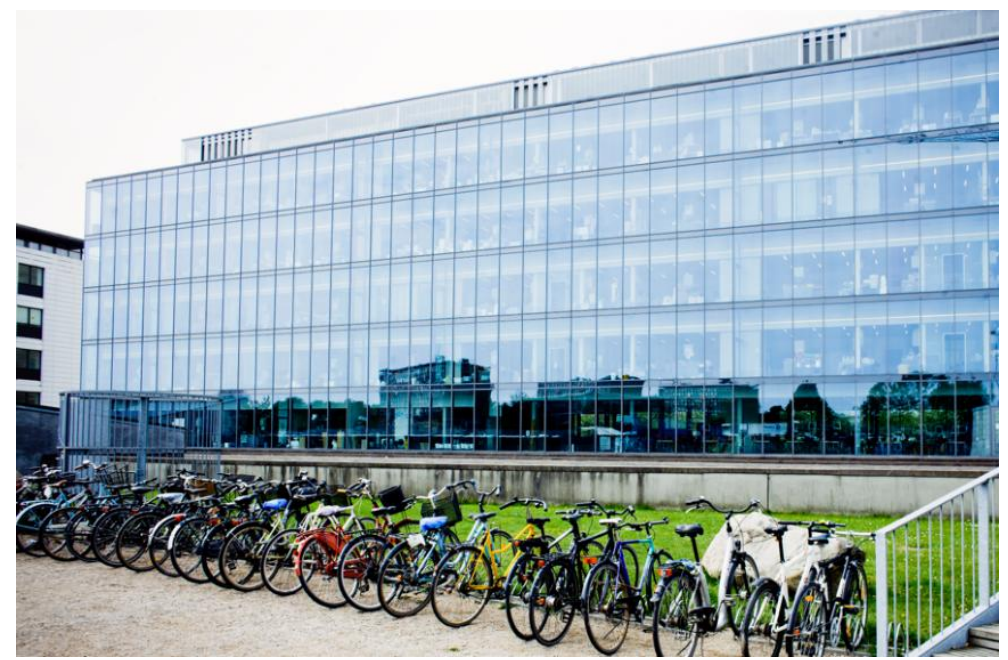

Barcelona. Overviews

of mouse genetics and nomenclature were given to emphasize their importance in the development of new models. How pathologists approach phenotyping mutant mice, mouse strain-specific background diseases, diseases in aging mice, and detailed descriptions of specific disease models were presented and discussed. Specific examples were discussed to illustrate how to unravel the underlying pathogenesis of the diseases under investigation. Interactive sessions using whole slide scanned images complemented the lectures. Scanned images were used to illustrate basic pathological processes in histologic sections. Interactive presentations were given to train attendees on the use of important mouse databases such as Mouse Genome Informatics (Eppig 2017a; Eppig 2017b) 
(http://www.informatics.jax.org/), which includes the Mouse Models of Human Cancer (MMHCdb; formerly the Mouse Tumor Biology Database, MTB) (Krupke 2017) and the Mouse Phenome Database (Bogue 2018). Pathbase, The European Mouse Pathology database (http://www.pathbase.net/) (Schofield 2004a; Schofield 2004b; Schofield 2010) provides another large image repository. Attendees were encouraged to make short presentations on their research projects that were critiqued and discussed with the experts in attendance.

\section{Dedicated Resources}

In addition to the 3 modules, supplemental training materials are available for the participants. A dedicated website is under construction (http://www.pathbio.org) with materials provided by the speakers. This includes PDFs of primary research and review articles and book chapters, Powerpoint ${ }^{\circledR}$ presentations, annotated images and webinars. Some of these webinars and detailed websites will be linked with other major open access databases upon completion. In addition, the PATHBIO webpage will include in the future specific teaching material, such as an X-ray Annotation Mouse Atlas, an Atlas for the identification of Mouse Lymphatics, a Comparative Embryology Mouse and Human Atlas, and a Mouse Craniofacial Development and Teeth Tutorial, among others.

Several websites are already available and useful for reviewing lesions diagnosed and photographed by established, board certified pathologists. Pathbase, the European Mouse Pathology Database, includes photomicrographs and whole slide scanned images for a large variety of normal and abnormal organs. The Mouse Tumor Biology Database (MTB) has cancer specific images and massive amount of primary molecular data. MTB works in close collaboration with the Pathbase group sharing materials. New modules are being created on how to accurately diagnose non-melanoma skin cancers in mice due to UV light,(Voigt 2019) DMBA/TPA two stage chemical carcinogenesis, (Sundberg 1997) papillomavirus, (Sundberg 2014) or spontaneous causes (Sundberg 1996).

The organizers and faculty hope that this program of training in mouse phenotyping will help to disseminate expertise and methodology and at the same time support career development of young scientists moving into this exciting area. The resources created and lessons learned from running this three-year program will contribute to the ultimate aim of the development of a European MSc course in mouse pathobiology.

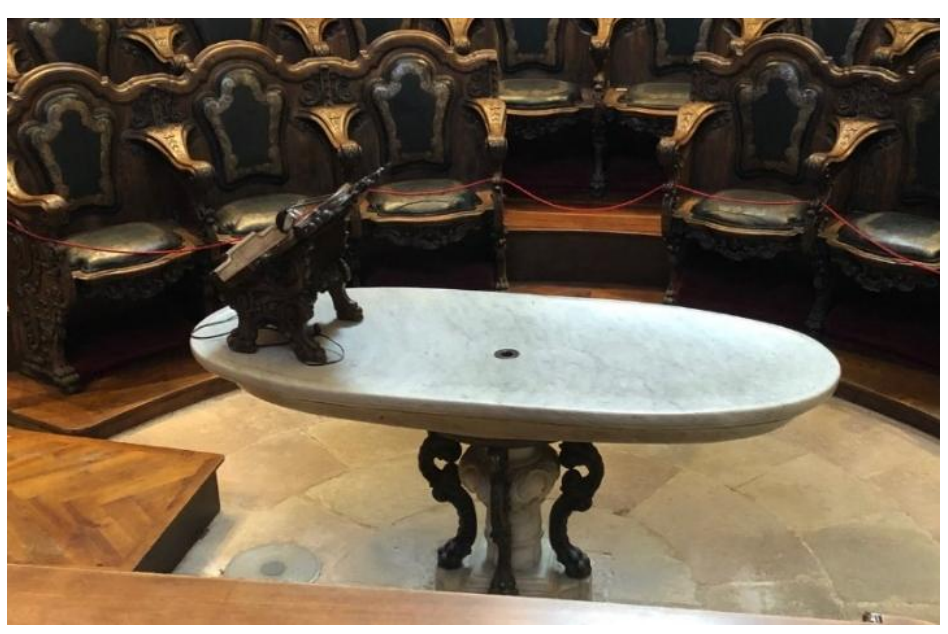

Fig. 4. Autopsy table in the Real Academia de Medicina amphitheater where the first organizational meeting was held.

\section{Administrative} organization. Each year the organizing committee meets. The first meeting was in March 2019 in Barcelona, Spain (Fig. 4). The overall organization was presented. This meeting brought the organizers of each module together with many of the faculty for these modules to allow the group to work 
together in person to lay out their programs. Each year such a meeting will be held in Lisbon, Portugal in 2020, Naples, Italy 2021, and Copenhagen, Denmark at the end of the project. The overall program will be discussed, changes made as deemed necessary based on feedback from the participants, and each teaching module refined for the upcoming year. Finally, the PATHBIO project will also provide the establishment of multilateral collaboration agreements for develop an application to an Erasmus Mundus Joint Master Degree on Mouse Precision Pathobiology under the Erasmus+ (Action 1) program. These agreements will be carried out between the PATHBIO partner universities and other institution of higher education that adhere to objectives of the project.

\section{List of abbreviations}

BRIC: Biotech Research \& Innovation Center (Copenhagen, Denmark)

PHENOMIN-ICS: PHENOMIN - Institut Clinique de la Souris (Illkirch, France)

CNR: Consiglio Nazionale delle Ricerche (Roma, Italy)

CT: Computed Tomography

FELASA: The Federation of European Laboratory Animal Science Associations

FMV-ULisboa: Faculdade de Medicina Veterinaria - Universidad de Lisboa (Portugal)

HMGU: Helmholtz Zentrum Muenchen Deustsches Forschungszentrum fuer Gesundheit und Umwelt GMBH, Munich, Germany

HREM: High-Resolution Episcopic Microscopy

ICLAS: International Council for Laboratory Animal Science

IGBMC: Institut de Génétique et de Biologie Moléculaire et Cellulaire (Illkirch, France)

IMG: Institute of Molecular Genetics (Prague, Czech Republic)

JAX: The Jackson Laboratory (Bar Harbor, ME, USA)

MRC: Medical Research Center (Harwell, UK)

MRI: Magnetic Resonance Imaging

OPT: Optical Projection Tomography

TCP: The Toronto Center for Phenogenomics (Canada)

UAB: Universitat Autònoma de Barcelona (Spain)

UCPH: University of Copenhagen (Denmark)

UCAM: The Chancellor, Masters and Scholar of the University of Cambridge (UK)

Unina: Università degli Studi di Napopoli - Federico II (Italy)

USFD: University of Sheffield (UK)

Acknowledgements: This work was supported by a grant from the Erasmus+ Knowledge Alliance of the Education, Audiovisual and Culture Executive Agency (EACEA) of the European Union (reference number 600803-EPP-1-2018-1-ESEPPKA2). Name of the project: Precision PathoBiology for Disease Models (PATHBIO). The authors want also to thank all partners involved in the PATHBIO Consortium.

\section{References}

Birling MC, Herault Y, Pavlovic G (2017) Modeling human disease in rodents by CRISPR/Cas9 genome editing. Mammalian genome: official journal of the International Mammalian Genome Society 28:291-301 
Bogue MA, Grubb SC, Walton DO, Philip VM, Kolishovski G et al (2018) Mouse Phenome Database: an integrative database and analysis suite for curated empirical phenotype data from laboratory mice. Nucleic acids research 46:D843-D850

Bradley A, Anastassiadis K, Ayadi A, Battey JF, Bell C et al (2012) The mammalian gene

function resource: the International Knockout Mouse Consortium. Mammalian genome: official journal of the International Mammalian Genome Society 23:580-586

Eppig JT (2017a) Mouse Genome Informatics (MGI) Resource: Genetic, Genomic, and Biological Knowledgebase for the Laboratory Mouse. ILAR J 58:17-41

Eppig JT, Smith CL, Blake JA, Ringwald M, Kadin JA et al (2017b) Mouse Genome Informatics (MGI): Resources for Mining Mouse Genetic, Genomic, and Biological Data in Support of Primary and Translational Research. Methods Mol Biol 1488:47-73

Krupke DM, Begley DA, Sundberg JP, Richardson JE, Neuhauser SB et al (2017)

The Mouse Tumor Biology Database: A Comprehensive Resource for Mouse Models of Human Cancer. Cancer Res 77:e67-e70

Schofield PN, Bard JB, Boniver J, Covelli V, Delvenne P et al (2004a) Pathbase: a new reference resource and database for laboratory mouse pathology. Radiat Prot Dosimetry 112:525-528

Schofield PN, Bard JB, Booth C, Boniver J, Covelli V et al (2004b) Pathbase: a database

of mutant mouse pathology. Nucleic acids research 32:D512-515

Schofield PN, Gruenberger M, Sundberg JP (2010) Pathbase and the MPATH ontology. Community resources for mouse histopathology. Veterinary pathology 47:10161020

Strong LC (1942) The origin of some inbred mice. Cancer Res 2:531-539

Sundberg JP, Hogan ME, King LE (1996) Normal biology and aging changes in skin and

hair. In Pathobiology of the aging mouse, Mohr U, Dungworth DL, Capen CC, Carlton WW, Sundberg JP, Ward JM, ed. Washington DC: ILSI Press, pp 303323

Sundberg JP, Sundberg BA, Beamer WG (1997) Comparison of chemical carcinogen skin

tumor induction efficacy in inbred, mutant, and hybrid strains of mice: morphologic variations of induced tumors and absence of a papillomavirus cocarcinogen. Mol Carcinog 20:19-32

Sundberg JP, Ward JM, HogenEsch H, Nikitin AY, Treuting PM et al (2012) Training pathologists in mouse pathology. Veterinary pathology 49:393-397

Sundberg JP, Stearns TM, Joh J, Proctor M, Ingle A et al (2014) Immune status, strain background, and anatomic site of inoculation affect mouse papillomavirus (MmuPV1) induction of exophytic papillomas or endophytic trichoblastomas. PloS one 9, e113582

Sundberg JP, Boyd K, Hogenesch H, Nikitin AY, Treuting PM et al (2018) Training mouse pathologists: 16(th) annual workshop on the pathology of mouse models of human disease. Lab Anim (NY) 47:38-40

Voigt AY, Michaud M, Tsai KY, Oh J, Sundberg JP (2019) Differential hairless mouse 
strain-specific susceptibility to skin cancer and sunburn. J Invest Dermatol 8:1837-1840 